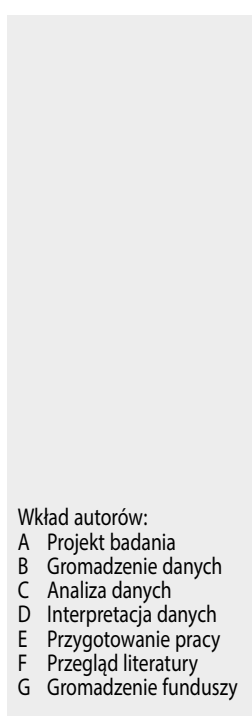

\title{
Teleporady logopedyczne w czasie pandemii COVID-19 dedykowane dorosłym użytkownikom implantu ślimakowego
}

\section{Speech therapy advice over the telephone during the COVID-19 pandemic for adult cochlear implant users}

\author{
Joanna Rostkowska, Dorota B. Wojewódzka
}

Instytut Fizjologii i Patologii Słuchu, Światowe Centrum Słuchu, Kajetany

\section{Streszczenie}

Artykuł zawiera informacje dotyczące pandemii COVID-19 w kontekście możliwości wykorzystania teleporad jako jednego ze sposobów zapobiegania rozprzestrzeniania się choroby. Autorki szczegółowo opisały przebieg i zastosowanie teleporad w zakresie rehabilitacji logopedycznej kierowanej do osób dorosłych, którym wszczepiono implant ślimakowy.

Słowa kluczowe: telemedycyna $\bullet$ trening słuchowy $\bullet$ CI • COVID-19

\begin{abstract} rehabilitation targeted at adults who use a cochlear implant.

Key words: telemedicine $\bullet$ auditory training $\bullet$ CI • COVID-19

Pandemia COVID-19

COVID-19 jest ostrą chorobą układu oddechowego spowodowaną przez koronawirusa SARS CoV-2, po raz pierwszy rozpoznaną w grudniu 2019 r. w chińskim mieście Wuhan. COVID-19 u większości zakażonych przebiega łagodnie. Jednak u około $14 \%$ pacjentów przebieg choroby jest ciężki, wymaga hospitalizacji i podawania tlenu, a w 5\% przypadków - przyjęcia na oddział intensywnej terapii [1]. Najpowszechniejszym rozpoznaniem u pacjentów z ciężkim przebiegiem COVID-19 jest ciężkie zapalenie płuc. W krytycznych przypadkach mogą wystąpić powikłania w postaci: zespołu ostrej niewydolności oddechowej, sepsy i wstrząsu septycznego, niewydolności wielonarządowej (w tym nerek i serca), a większość osób $\mathrm{w}$ tym stanie wymaga wentylacji mechanicznej [2]. Zwiększone ryzyko ciężkiego lub krytycznego przebiegu choroby, a także zgonu występuje u osób starszych (po 60 roku
\end{abstract}

The article contains information about the COVID-19 pandemic and the possibility of using telemedicine as one of the ways to prevent the spread of the disease. The authors described in detail the course and use of telemedicine over the phone in speech therapy

życia) i osób ze współistniejącymi chorobami, takimi jak choroby układu krążenia i cukrzyca [3,4]. Obecnie choroba COVID-19 występuje na wszystkich kontynentach globu. Z tego względu w dniu 11 marca 2020 r. Światowa Organizacja Zdrowia (WHO) ogłosiła pandemię COVID-19 i określiła tę chorobę jako duże zagrożenie dla zdrowia publicznego [5]. Pandemia zmusiła rządy wielu krajów do wprowadzenia zmian w życiu społecznym.

Także w Polsce, od 20 marca 2020, zgodnie z rozporządzeniem Ministra Zdrowia wprowadzono stan epidemii spowodowany koronawirusem SARS CoV-2 [6]. W rezultacie wprowadzono liczne obostrzenia, takie jak: zamknięcie placówek edukacyjnych, wstrzymanie międzynarodowych połączeń lotniczych i kolejowych, zakaz zgromadzeń, przemieszczania się, rekomendowanie ograniczania do niezbędnego minimum wychodzenia $\mathrm{z}$ domu, zamknięcie sklepów innych niż spożywcze i apteki.

Adres autora: Joanna Rostkowska, Światowe Centrum Słuchu, Instytut Fizjologii i Patologii Słuchu, ul. Mokra 17, Kajetany, 05-830 Nadarzyn, e-mail: j.rostkowska@ifps.org.pl 


\section{Świadczenia telemedyczne - teleporady}

W celu minimalizowania ryzyka transmisji choroby COVID-19 zmianie uległo funkcjonowanie placówek medycznych. Narodowy Fundusz Zdrowia (NFZ) wskazał na możliwość wykonywania i rozliczania porad lekarskich realizowanych $w$ ramach świadczeń $z$ zakresu podstawowej opieki zdrowotnej (POZ) oraz ambulatoryjnej opieki specjalistycznej (AOS) z wykorzystaniem systemów teleinformatycznych lub innych systemów łączności [7]. W wypadku świadczeń z zakresu logopedii zapis taki został ujęty w załączniku 1a do zarządzenia NFZ opublikowanego 11 marca 2020 [8]. Dzięki takim decyzjom, korzystając z narzędzi teleinformatycznych, można kontynuować rehabilitację logopedyczną, efektywną tylko wtedy, gdy prowadzi się ją systematycznie. A przede wszystkim można bezpiecznie kontynuować rehabilitację logopedyczną u pacjentów po 60 roku życia, bez narażania ich na opuszczanie miejsca zamieszkania i związane $\mathrm{z}$ tym zwiększone ryzyko zachorowania.

Osoby starsze to grupa odbiorców sceptycznie nastawiona do telemedycyny - prawdopodobnie ze względu na niewielką świadomość zagadnienia i obawy związane $\mathrm{z}$ używaniem nowych technologii. Jednak polskie prawo nie precyzuje, jakiego systemu łączności należy używać do realizowania świadczeń telemedycznych [9]. Część teleporad - bez obniżenia merytorycznej jakości usługi - może odbywać się dzięki połączeniom telefonicznym. Wyniki badań Bujnowskiej-Fedak i wsp. wskazują, że coraz więcej osób starszych bez trudu korzysta z telefonu komórkowego [10]. W latach 2017-2018 Rostkowska przeprowadziła badania dotyczące posługiwania się telefonem komórkowym wśród 100 pacjentów Instytutu Fizjologii i Patologii Słuchu, którzy ogłuchli postlingwalnie i otrzymali implant ślimakowy po 60 roku życia. Wszyscy ankietowani stwierdzili, że komunikują się przez telefon - odbywają rozmowy oraz wysyłają i odbierają wiadomości tekstowe [1]. Otrzymane wyniki potwierdziły powszechność używania telefonu w tej grupie osób.

\section{Teleporady logopedyczne}

Świadczenie telemedyczne z zakresu logopedii jest równoprawnym świadczeniem zdrowotnym udzielanym zgodnie $\mathrm{z}$ obowiązującą wiedzą medyczną, tak jak osobista stacjonarna porada logopedyczna (wykonana w gabinecie). Jego przebieg i podsumowanie musi zostać wpisane do dokumentacji medycznej pacjenta $\mathrm{z}$ dodatkową informacją, że odbyła się przy użyciu systemów teleinformatycznych. Pozostałe zasady przeprowadzenia świadczenia, dotyczące m.in. wykorzystania aktualnej wiedzy logopedycznej, etyki zawodowej i należytej staranności, pozostają niezmienne.

Dotychczas w IFPS realizowano model synchroniczny teleporad z zakresu logopedii, w którym działania polegają na równoległym, jednoczesnym kontakcie specjalisty z pacjentem przy pomocy systemów teleinformatycznych, zapewniających właściwą jakość obrazu i dźwięku [12], przy założeniu, że połączenie odbywa się między dwoma współpracującymi ośrodkami medycznymi $[13,14]$. Zmiany wprowadzone ze względu na epidemię umożliwiły realizację teleporad bezpośrednio z pacjentem niezależnie od miejsca, w którym się on faktycznie znajduje.

Jednak należy pamiętać, że teleporada jest specyficzną formą kontaktu i wymaga opracowania szczegółowych wytycznych oraz procedur postępowania, które ze względu na rozwój techniki i swój zakres muszą ulegać stałej aktualizacji. Najważniejsze informacje dotyczące obecnie obowiązujących zasad udzielania świadczeń telemedycznych zawarto w dokumencie przygotowanym przez Fundację Telemedycznej Grupy Roboczej. Eksperci umieścili $\mathrm{w}$ nim m.in. algorytm podstawowej procedury komunikacji między świadczeniodawcą a świadczeniobiorcą w czasie teleporady (rycina 1) [9].

Wzorując się na modelu podstawowej procedury komunikacji między świadczeniodawcą a świadczeniobiorcą w czasie teleporady, autorki artykułu przygotowały model teleporady z zakresu logopedii (rehabilitacji logopedycznej) przeznaczonej dla dorosłej osoby postlingwalnie ogłuchłej, korzystającej z implantu ślimakowego, która uczestniczy w stacjonarnym programie rehabilitacji słuchowej, zawierającym także trening korzystania $\mathrm{z}$ telefonu [15] (rycina 2). Algorytm podstawowy został uzupełniony o wysłanie wiadomości tekstowej, przypomnienie o kolejnej wizycie umówionej zgodnie z grafikiem rehabilitacji oraz o konieczności zapoznania się z wiadomością tekstową wysłaną przed kolejną wizytą. Natomiast weryfikację tożsamości pacjenta oparto tylko na imieniu i nazwisku oraz rozpoznaniu głosu pacjenta przez terapeutę. Jest to wystarczające, ponieważ logopeda i pacjent znają się osobiście $\mathrm{z}$ terapii stacjonarnej, prowadzonej w ośrodku.

W celu przybliżenia rzeczywistego przebiegu takiej teleporady poniżej zamieszczono przykładową teleporadę z zakresu logopedii (rehabilitacji logopedycznej) przeprowadzoną z osobą 67-letnią, ogłuchłą postlingwalnie, która od roku jest użytkownikiem systemu implantu ślimakowego i bierze udział w treningu słuchowym [15]. Pacjentowi zaproponowano trzy ćwiczenia słuchowe:

1. Ćwiczenie z zakresu dyskryminacji dwóch wyrazów. W materiale językowym znalazły się pary wyrazów o takiej samej liczbie sylab, ale różniące się samogłoską, spółgłoską lub czytane wspak.

2. Ćwiczenie z zakresu rozpoznawania zdań ze zbioru półotwartego. W materiale językowym umieszczono zestawy zdań ze wskazówką tematyczną.

3. Ćwiczenie $z$ zakresu rozpoznawania mowy w zestawach otwartych. W materiale językowym zawarto zdania, których początek sugeruje, co będzie w drugiej części zdania (rycina 3).

Pacjenci, którzy zdecydowali się na kontynuację rehabilitacji logopedycznej w trybie teleporad, oceniają je jako przydatne i potrzebne. Deklarują dalsze uczestnictwo w tej formie terapii.

Prowadzenie rehabilitacji logopedycznej drogą telefoniczną nie jest łatwe. Wymaga: dobrej znajomości pacjenta, a zwłaszcza jego możliwości słuchowych i językowych, przygotowania materiału językowego adekwatnego do wieku, 
wykształcenia oraz zainteresowań pacjenta, zabezpieczenia odpowiedniej ilości materiału językowego do ćwiczeń na czas trwania porady z uwzględnieniem konieczności utrzymania specyficznego tempa pracy, które narzuca ta forma kontaktu, i konieczności podtrzymania uwagi pacjenta. Można zastanowić się nad nagrywaniem porad, oczywiście za zgodą pacjenta, żeby lepiej monitorować popełniane przez niego błędy i czynione postępy.

\section{Telemedycyna w IFPS}

Od początku istnienia IFPS jest zorientowany na rozwijanie nowych technologii i wprowadzanie daleko idących zmian w leczeniu i terapii zaburzeń słuchu i mowy, a jednym ze sposobów wprowadzania nowoczesnych rozwiązań jest zastosowanie telemedycyny. Najważniejsze osiągnięcia Instytutu z tego obszaru to:
- opracowanie programów diagnostyczno-rehabilitacyjnych: „Słyszę”, „Mówię”, „Widzę”, „Tinnitus”, dostępnych na portalu internetowym [16];

- Krajowa Sieć Teleaudiologii, dzięki której możliwe są telekonsultacje z zakresu diagnozy, fittingu czy rehabilitacji między Światowym Centrum Słuchu w Kajetanach i 20 współpracującymi ośrodkami $[17,18,19]$.

Wymienione przedsięwzięcia są nie tylko wykorzystywane klinicznie, lecz także były wielokrotnie nagradzane w kraju i za granicą [20].

\section{Podsumowanie}

1. Obecnie telemedycyna stała się jednym $\mathrm{z}$ narzędzi ograniczającym rozprzestrzenianie się pandemii COVID-19.

Tabela 1. Model podstawowej procedury komunikacji między świadczeniodawcą a świadczeniobiorcą w czasie teleporady Table 1. Model of the basic communication procedure between the provider and the recipient during telemedicine

\begin{tabular}{|c|c|}
\hline Lp. & Sposób postępowania \\
\hline 1. & Powitanie pacjenta i wzajemne przedstawienie się. Poinformowanie o zachowaniu tajemnicy lekarskiej. \\
\hline 2. & Upewnienie się, że pacjent poprawnie odbiera przekaz. \\
\hline 3. & Przekazanie informacji, że w razie problemów technicznych należy natychmiast o nich poinformować. \\
\hline 4. & $\begin{array}{c}\text { Weryfikacja tożsamości pacjenta i ustalenie miejsca przebywania chorego. Poproszenie pacjenta o numer telefonu, } \\
\text { jeżeli lekarz go nie zna. }\end{array}$ \\
\hline 5. & Poinformowanie pacjenta o charakterze świadczenia i jego ograniczeniach. \\
\hline 6. & $\begin{array}{c}\text { Poinformowanie pacjenta, że świadczenie nie zastępuje standardowej terapii, a pacjent w każdej chwili może udać się } \\
\text { na osobistą wizytę. }\end{array}$ \\
\hline 7. & Poinstruowanie pacjenta, że w razie pogorszenia stanu zdrowia powinien udać się do lekarza. \\
\hline 8. & Udzielenie świadczenia. \\
\hline 9. & Upewnienie się, że pacjent zrozumiał przekazane mu informacje i zalecenia w ramach świadczenia. \\
\hline 10. & Zakończenie teleporady. \\
\hline
\end{tabular}

Tabela 2. Model teleporady z zakresu rehabilitacji logopedycznej przeznaczonej dla dorosłej osoby postlingwalnie ogłuchłej korzystającej z implantu ślimakowego, która uczestniczy w stacjonarnym programie rehabilitacji logopedycznej

Table 2. Model of a telephone visit in the field of speech therapy for an adult using a cochlear implant who participates in a stationary speech therapy program

\begin{tabular}{|c|c|}
\hline Lp. & Sposób postępowania \\
\hline 1. & $\begin{array}{l}\text { Wysłanie wiadomości tekstowej (SMS) na numer telefonu pacjenta z informacją, jakiego rodzaju ćwiczenia } \\
\text { będą wykonywane w czasie teleporady. Opisanie polecenia, które będzie wykonywał pacjent. }\end{array}$ \\
\hline 2. & Powitanie pacjenta i wzajemne przedstawienie się. \\
\hline 3. & Upewnienie się, że pacjent poprawnie odbiera przekaz. \\
\hline 4. & Przekazanie informacji, że w razie problemów technicznych należy natychmiast o nich poinformować. \\
\hline 5. & Ustalenie miejsca, w którym przebywa pacjent. \\
\hline 6. & Poinformowanie pacjenta o charakterze świadczenia. \\
\hline 7. & Udzielenie świadczenia. \\
\hline 8. & $\begin{array}{c}\text { Przypomnienie o terminie kolejnej umówionej teleporady oraz o tym, by pacjent zapoznał się z treścią SMS, } \\
\text { który będzie wysłany przed kolejną wizytą. }\end{array}$ \\
\hline 9. & Zakończenie teleporady. \\
\hline
\end{tabular}


Tabela 3. Teleporada z zakresu rehabilitacji logopedycznej przygotowana dla 67-latka korzystającego z implantu ślimakowego Table 3. Telephone visit in the field of speech therapy rehabilitation prepared for a 67-year-old person using a cochlear implant

\begin{tabular}{|c|c|c|c|}
\hline Lp. & \multicolumn{3}{|c|}{ Sposób postępowania } \\
\hline 1. & \multicolumn{3}{|c|}{$\begin{array}{l}\text { Wiadomość tekstowa (SMS) przesłana do pacjenta przed teleporadą: W czasie wizyty wykonamy } 3 \text { rodzaje ćwiczeń. } \\
\text { W pierwszym ćwiczeniu trzeba będzie powiedzieć, czy usłyszane dwa słowa są takie same czy różne. Drugie ćwiczenie } \\
\text { będzie polegało na powtórzeniu zdań o tematyce: samochód, epidemia COVID-19, rośliny. W trzecim ćwiczeniu trzeba } \\
\text { będzie powtórzyć zdania, w których początek sugeruje zakończenie. }\end{array}$} \\
\hline 2. & \multicolumn{3}{|c|}{ Dzień dobry. Nazywam się ... Czy rozmawiam z ...? } \\
\hline 3. & \multicolumn{3}{|c|}{ Czy dobrze mnie Pan słyszy? Jeśli czegoś Pan nie zrozumie, proszę o tym powiedzieć. Czy przeczytał Pan SMS-a ode mnie? } \\
\hline 4. & \multicolumn{3}{|c|}{$\begin{array}{r}\text { Jeśli będą problemy ze sprzętem, np. trzaski, piski lub w ogóle nie będzie mnie słychać, proszę o tym powiedzieć. } \\
\text { Jeśli rozmowa zostanie przerwana, to zadzwonię do Pana jeszcze raz. }\end{array}$} \\
\hline 5. & \multicolumn{3}{|c|}{ Gdzie teraz Pan przebywa? } \\
\hline \multirow[t]{14}{*}{6.} & \multicolumn{3}{|c|}{ Przypominam, że ćwiczenia słuchowe, które za chwilę przeprowadzę, to teleporada z zakresu rehabilitacji logopedycznej. } \\
\hline & \multicolumn{3}{|c|}{$\begin{array}{l}\text { 1. Powiem dwa wyrazy, proszę o wysłuchanie ich i odpowiedź, czy są one takie same czy różne. } \\
\text { Czy zrozumiał Pan polecenie? Uwaga, zaczynam mówić... }\end{array}$} \\
\hline & las - lis & bal - ból & kit - kit \\
\hline & bat - but & kot - kit & syn - sen \\
\hline & sam - sum & len - lin & ruch - róg \\
\hline & rok - ryk & kos - sok & krab - krab \\
\hline & rum - mur & los - sol & bór - bór \\
\hline & luz - sól & róż - róż & żak - rzek \\
\hline & tam - mat & łuk - kuł & tok - kot \\
\hline & pąk - pąk & las - sal & puk - kup \\
\hline & lin - Nil & kit - tik & bór - mur \\
\hline & lis - lis & daj-maj & $d a ̨ b-d a ̨ b$ \\
\hline & mit - kit & paw - paw & nić - pić \\
\hline & kok - lok & lód - lód & kruk - mruk \\
\hline
\end{tabular}

2a. Usłyszy Pan zdania. Wszystkie będą dotyczyły tematu „samochód”. Proszę powtórzyć zdania.

Czy zrozumiał Pan polecenie? Uwaga, zaczynam mówić...

Zgubiłam kluczyki i dokumenty.

Kot sąsiada często przesiaduje na rozgrzanej masce.

Ten czerwony lakier ma piękny odcień.

Prawo jazdy mojego męża straciło ważność.

Do bagażnika zmieszczą się tylko dwie walizki i torba z jedzeniem.

Gdzie jest trójkąt ostrzegawczy?

Marzę o pojeździe na prąd.

Nie lubię tam tankować.

Potrafię jeździć, ale nie robię tego często.

Moja koleżanka wszędzie zaparkuje.

2b. Usłyszy Pan zdania. Wszystkie będą dotyczyły tematu „epidemia COVID-19”. Proszę powtórzyć zdania.

Czy zrozumiat Pan polecenie? Uwaga, zaczynam mówić...

Trzeba myć ręce co najmniej 30 sekund.

Pamiętaj, żeby wziąć maseczkę.

W tym sklepie można kupić jednorazowe rękawiczki w dobrej cenie.

Wyjdę z domu, tylko gdy będę musiała.

Wnuk mnie teraz nie odwiedza, tylko do mnie dzwoni.

Tylko ci pomacham, bo teraz lepiej nie podawać ręki.

Wiem, jakie są objawy COVID-19.

Gdy źle się poczuję, zadzwonię na pogotowie.

Teraz szczególnie o siebie dbam.

Nie mam gorączki i nie kaszlę.

Twój kuzyn jest na kwarantannie.

Przy wejściu do sklepu stoi płyn do dezynfekcji rąk.

Czy wiesz, co to są szpitale jednoimienne?

$\mathrm{Na}$ tym spotkaniu nikt nie zachowywał dystansu społecznego.

W aptece mogą przebywać tylko dwie osoby. 


\begin{tabular}{|c|c|}
\hline Lp. & Sposób postępowania \\
\hline & $\begin{array}{l}\text { 2c. Usłyszy Pan zdania. Wszystkie będą dotyczyły tematu „rośliny”. Proszę powtórzyć zdania. } \\
\text { Czy zrozumiał Pan polecenie? Uwaga, zaczynam mówić... }\end{array}$ \\
\hline & Sąsiedzi mają dużo kwiatów na balkonie. \\
\hline & Wszystkie róże już przekwitty. \\
\hline & Te tulipany mają takie piękne nazwy. \\
\hline & Koszenie trawy to ulubione zajęcie mojego brata. \\
\hline & $\begin{array}{l}\text { NIe mam rękı do kwIatow. } \\
\text { Kotek schował sie w paprociach. }\end{array}$ \\
\hline & Niezapominajki są niebieskie. \\
\hline & Zawsze chciałam pracować w kwiaciarni. \\
\hline & Ale tu zielono! \\
\hline & Książka z zasuszonymi roślinami to zielnik. \\
\hline & $\begin{array}{l}\text { 3. Ustyszy Pan zdania. Początek zdania sugeruje, co będzie w jego drugiej części. Proszę powtórzyć zdania. } \\
\text { Czy zrozumiał Pan polecenie? Uwaga, zaczynam mówić... }\end{array}$ \\
\hline & Usiądź na tym fotelu. \\
\hline & Zupę zjem tyżką. \\
\hline & Przy stole stoją krzesła. \\
\hline & Rano jem śniadanie. \\
\hline & Pójdę na film do kina. \\
\hline & Dom jest zbudowany z cegieł. \\
\hline & Po ulicy jedzie samochód. \\
\hline & Na imieniny dostałam kwiaty. \\
\hline & Położę głowę na poduszce. \\
\hline & Mam pieniądze w portfelu. \\
\hline 8. & To już wszystkie ćwiczenia. Kolejna teleporada odbędzie się zgodnie z grafikiem rehabilitacji dnia.... Przed teleporadą \\
\hline 9. & Dziękuję bardzo. Do ustyszenia. \\
\hline
\end{tabular}

2. Usługi telemedyczne są korzystnym rozwiązaniem, zwłaszcza dla osób starszych.

3. Teleporada $z$ zakresu logopedii jest równoprawnym świadczeniem zdrowotnym takim jak osobista, stacjonarna porada logopedyczna wykonana w gabinecie.

4. Rehabilitacja logopedyczna może być prowadzona za pomocą łącza telefonicznego.

\section{Piśmiennictwo}

1. The Novel Coronavirus Pneumonia Emergency Response Epidemiology Team. Vital surveillances: The epidemiological characteristics of an outbreak of 2019 novel coronavirus diseases (COVID-19) - China, 2020. China CDC Weekly, 2020; 2(8): 113-22.

2. Yang X, Yu Y, Xu J, Shu H, Xia J, Liu H i wsp. Clinical course and outcomes of critically ill patients with SARS-CoV-2 pneumonia in Wuhan, China: a single-centered, retrospective, observational study. Lancet Respir Med, 2020; 8(5): 475-81.

3. Velavan TP, Meyer CG. The COVID-19 epidemic. Trop Med Int Health, 2020; 25(3): 278-80.

4. World Health Organization. Postępowanie kliniczne w ostrym zakażeniu dróg oddechowych o ciężkim przebiegu (SARI) w przypadku podejrzenia choroby COVID-19. Wytyczne tymczasowe, 13 marca 2020, https://apps.who.int/iris/bitstream/ handle/10665/331809/WHO-2019-nCoV-clinical-2020.4-pol. pdf? sequence $=1$ \&isAllowed=y [dostęp: 21.06 .2020 ].
5. Rozwiązania z zakresu telemedycyny przyczyniają się do poprawy dostępności, jakości i bezpieczeństwa opieki medycznej, także tej specjalistycznej.

6. Telemedycyna znosi bariery geograficzne i redukuje koszty dojazdów do ośrodka świadczącego usługi medyczne.
5. Guo YR, Cao QD, Hong ZS, Tan YY, Chen SD, Jin HJ i in. The origin, transmission and clinical therapies on coronavirus disease 2019 (COVID-19) outbreak - an update on the status. Mil Med Res, 2020; 7(1): 11.

6. Rozporządzenie Ministra Zdrowia z dnia 20 marca $2020 \mathrm{r}$. w sprawie ogłoszenia na obszarze Rzeczypospolitej Polskiej stanu epidemii. Dz. U. z 2020, poz. 491.

7. Narodowy Fundusz Zdrowia. Komunikat do świadczeniodawców POZ w związku z zapobieganiem, przeciwdziałaniem i zwalczaniem COVID-19, 15.03.2020, https://www.nfz.gov.pl/ aktualnosci/aktualnosci-centrali/komunikat-dla-swiadczeniodawcow,7644.html [dostęp: 21.06.2020].

8. Narodowy Fundusz Zdrowia. Zarządzenia Prezesa NFZ nr 182/2019/DSOZ, 31.12.2019, https:/www.nfz.gov.pl/zarzadzeniaprezesa/zarzadzenia-prezesa-nfz/zarzadzenie-nr-1822019dsoz, 7104.html [dostęp: 21.06.2020].

9. Naczelna Izba Lekarska. Telemedycyna - wskazówki dla lekarzy i pacjentów, https://nil.org.pl/aktualnosci/4609-telemedycynawskazowki-dla-lekarzy-i-pacjentow na dzień 21.06.2020 [dostęp: 21.06.2020]. 
10. Bujnowska-Fedak MM, Staniszewski A, Steciwko A. A survey of Internet use for health purposes in Poland. J Telemed Telecare, 2007; 13(5): 16-19.

11. Rostkowska J, Wojewódzka B, Geremek-Samsonowicz A, Pankowska A, Olędzka M, Dębińska- Khalil M i wsp. Depresja a zastosowanie implantu ślimakowego u osób po 65 roku życia [Abstrakt]. II Konferencja Naukowa „Wytyczne w otorynolaryngologii, audiologii i foniatrii”, 9-11.03.2017, Zakopane. Now Audiofonol, 2017; 6 (Suppl.): 36-37.

12. Swanepoel D, Hall J. A systematic review of telehealth applications in audiology. Telemedicine and e-Health, 2010; 16(2): 181-200.

13. Pankowska A, Rostkowska J, Skarżyński H. Telerehabilitacja dorosłych pacjentów korzystających z aparatów słuchowych i/lub implantów ślimakowych. Now Audiofonol, 2015; 4(2): 81-85.

14. Solnica J, Pankowska A, Skarżyński H. Telerehabilitacja - nowa forma pomocy pacjentom korzystającym z systemu implantu ślimakowego w ramach programu opieki pooperacyjnej. Now Audiofonol, 2012; 1(3): 35-38.
15. Skarżyński H, Szuchnik J, Mueller-Malesińska M. Implanty ślimakowe - rehabilitacja. Warszawa: Stowarzyszenie Przyjaciół Osób Niesłyszących i Niedosłyszących „Człowiek - Człowiekowi”; 2004.

16. Telezdrowie.pl, https://www.telezdrowie.pl [dostęp: 21.06.2020].

17. Skarżyński PH, Wąsowski A, Skarżyński H, Bruski Ł, Pierzyńska I. Telemedyczne rozwiązania w diagnostyce, leczeniu i rehabilitacji pacjentów po wszczepieniu implantów ślimakowych (leczenie częściowej głuchoty). Otorynolaryngologia - Przegląd Kliniczny, 2013; 12: 30-31.

18. Skarżyński PH, Wąsowski A, Skarżyński H, Bruski Ł, Pierzyńska I. Telemedyczne rozwiązania w diagnostyce, leczeniu i rehabilitacji pacjentów po wszczepieniu implantów ślimakowych. Now Audiofonol, 2013; 2(2): 45.

19. Wąsowski A, Skarżyński H, Bruski Ł, Lorens A, Obrycka A, Walkowiak A i wsp. Metoda zdalnego dopasowania implantu (telefitting) w Ogólnopolskiej Sieci Teleaudiologii. Now Audiofonol, 2012; 1(3): 39-43.

20. World Hearing Center. Krajowa Sieć Teleaudiologii. Nagrody, medale, wyróżnienia, http://telefitting.ifps.org.pl/?site=nagrody [dostęp: 21.06.2020]. 